\title{
Julius Caesar Arantius (Giulio Cesare Aranzi, 1530-1589) and the hippocampus of the human brain: history behind the discovery
}

\author{
Shyamal C. Bir, MD, PhD, Sudheer Ambekar, MD, Sunil Kukreja, MD, and Anil Nanda, MD, MPH \\ Department of Neurosurgery, Louisiana Health-Shreveport, Louisiana
}

\begin{abstract}
Julius Caesar Arantius is one of the pioneer anatomists and surgeons of the 16th century who discovered the different anatomical structures of the human body. One of his prominent discoveries is the hippocampus. At that time, Arantius originated the term hippocampus, from the Greek word for seahorse (hippos ["horse"] and kampos ["sea monster"]). Arantius published his description of the hippocampus in 1587, in the first chapter of his work titled De Humano Foetu Liber. Numerous nomenclatures of this structure, including "white silkworm," "Ammon's horn," and "ram's horn" were proposed by different scholars at that time. However, the term hippocampus has become the most widely used in the literature.
\end{abstract}

http://thejns.org/doi/abs/10.3171/2014.11.JNS132402

KEY WORDS Giulio Cesare Aranzi; hippocampus; discovery; history

$\mathrm{T}$ HE hippocampus is one of the major components of the human brain and belongs to the limbic system. It plays crucial roles in long-term memory, learning, and emotional and sexual behavior. ${ }^{12}$ The history of medicine is rich in the pioneers who dedicated their lives to advance modern neuroscience. There was an influx of refugee scholars from Greece to Italy during the capture of Constantinople by Turkey in 1453. At that time, the universities in northern Italy, including Bologna and Padua, were full of local and refugee scholars, and these two universities led the advances in medicine and surgery. Therefore, there was an outburst of creative and contemporary research activities in medicine in the 15th and 16th centuries.

In particular, Andreas Vesalius (1514-1564), Matteo Realdo Colombo (1516-1559), Leonardo Fioravanti (15171588), Bartolomeo Eustachi (c. 1520-1574), Gabriel Fallopius (1523-1562), Hieronymus Fabricius ab Aquapendente (1537-1619), and Giulio Cesare Aranzi (1530-1589) were the renowned scholars in medicine from these two universities. They made a major contribution to the development and advancement of anatomy and surgery at that time. During the 16th-century Renaissance, anatomy-based surgical practice was very popular. Among the aforementioned scholars, Giulio Cesare Arantius, an Italian anatomist and surgeon, was one of the pioneers in the discoveries of human anatomy. Arantius was a conscientious and impartial observer to whom the field of human anatomy owes several discoveries.? The hippocampus is one of Arantius' most important discoveries, along with other important contributions in anatomy including the eye and eyelids, the fetus, and the heart. However, the history of the hippocampus and Arantius has not been reported extensively. In this historical article, we present the details of Arantius' life and his pioneering work on the discovery of the hippocampus.

\section{Julius Caesar Arantius (1530-1589)}

Julius Caesar Arantius (Giulio Cesare Aranzi), the son of Ottaviano di Jacopo and Maria Maggi, was born in Bologna, Italy, in 1530, and grew up in that city. Because of his parents' poverty, he conducted his studies under the direct supervision of his uncle, Bartolomeo Maggi (14771552), an outstanding surgeon at the University of Bologna and principal court physician of Julius III. Arantius was honored with a doctorate in medicine at Bologna in May 1556 , and shortly thereafter he was recruited as a lecturer of surgery at the University of Bologna. Fourteen years later, in 1570, he took initiatives to separate surgery and anatomy into individual professorships, and he held both

SUBMITTED November 11, 2013. ACCEPTED November 11, 2014.

INCLUDE WHEN CITING Published online January 9, 2015; DOI: 10.3171/2014.11.JNS132402.

DISCLOSURE The authors report no conflict of interest concerning the materials or methods used in this study or the findings specified in this paper. 
tenured positions in anatomy and surgery for 19 years, until his death on April 7, 15896,22 (Fig. 1).

\section{Arantius and the Discovery of the Hippocampus}

By the 16th century, the old understanding of anatomy was replaced by more open-minded, experimental observations of the human body. Arantius became one of the prominent anatomists and representatives of human anatomical experimentation in Bologna, Italy. ${ }^{7} \mathrm{He}$ began his personal experience in anatomical dissection at the University of Bologna during his student life in the anatomical theater of Archiginnasio, which is well known today as La Biblioteca dell'Archiginnasio. He assisted his uncle Bartolomeo Maggi in anatomical dissection and became his uncle's favorite pupil. While Arantius was a lecturer at the University of Bologna, his favorite pupil, renowned surgeon Gaspare Tagliacozzi, assisted him with dissections. ${ }^{4}$ Demonstrations of anatomy at the University of Bologna were based on the performance of public dissection on the human body. However, this was hard to maintain because there was no separate department and chair of anatomy. Thereafter, as Professor and Chair of Surgery and Anatomy, Arantius established the latter as a major branch of medicine for the first time, thus making it easier to teach anatomy.

The outstanding scientific and practical education Arantius received from his uncle and his dedication to anatomical discovery led Arantius to distinguish different structures of the brain, including the hippocampus. Unfortunately, Arantius published neither an illustration nor a detailed description of the procedure, and therefore the perspective from which Arantius pictured the hippocampus as a seahorse remains unknown. However, later on, Félix Vicq d'Azyr and Gustav Retzius practiced a method of anatomical dissection in which part of the parahippocampal cortex and subjacent white matter is stripped off, which exposes the ventral surface of the dentate gyrus. This method of dissection from the ventral surface of the brain displays a view of the hippocampus in which it looks like a seahorse. Probably Arantius used this method of dissection because his famous contemporary, Costanzo Varolio, introduced the same method. ${ }^{9}$

Centuries in the past, analogous terminology was used to describe some special part of neuroanatomy. Thus various terms related to zoology, including the names for seahorse, silkworm, ram, turtle, and hippopotamus, were introduced in neuroanatomical terminology. However, Arantius' naming system was probably influenced by both zoology and mythology. Seahorses are very common in the Mediterranean, and contemporary descriptions of different creatures including the seahorse were noted in various books of ichthyology at the time, and these might have influenced Arantius to coin the name hippocampus..$^{10}$ Evidence of the zoological influence is seen by his use of the term hippocampus or seahorse after observing the curled morphology of an intraventricular formation of the cerebrum that looked more or less like a seahorse. At the same time, the paintings from Giuseppe Arcimboldo's water series contributed to the popular images of sea creatures,

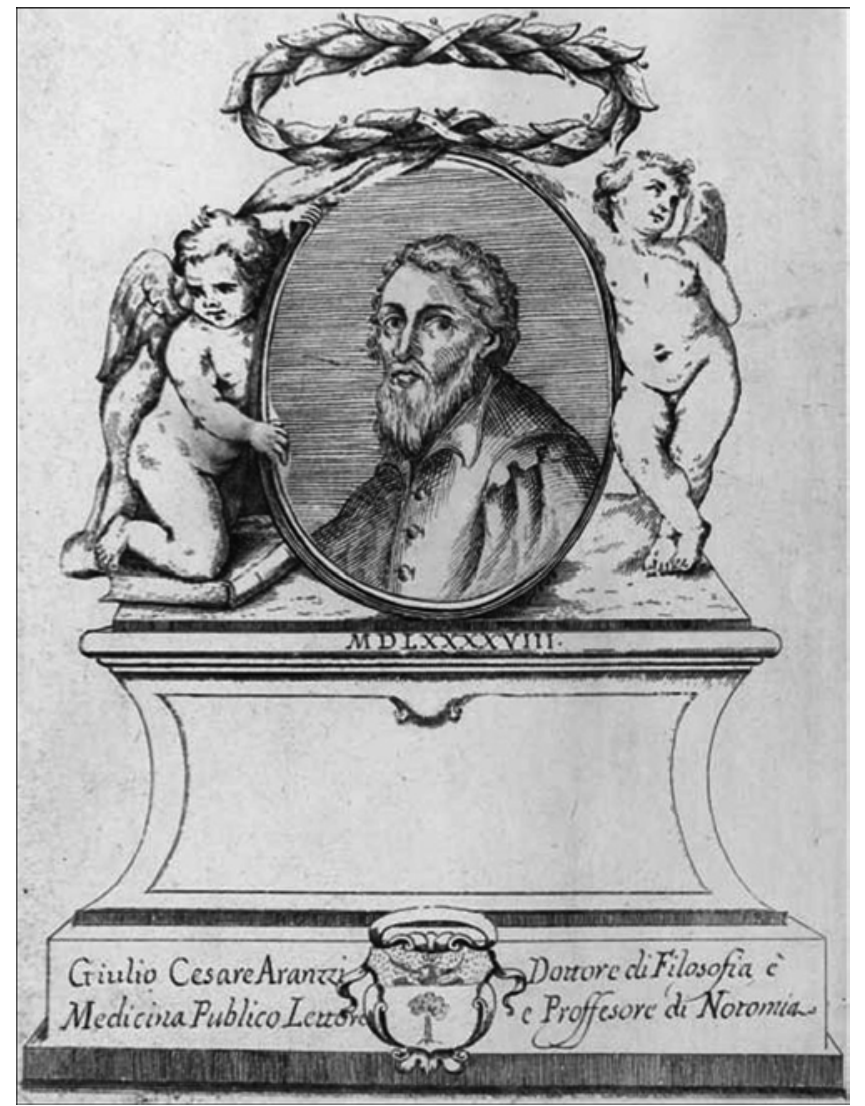

FIG. 1. Portrait of Julius Caesar Arantius (Giulio Cesare Aranzi, 15301589). Courtesy of Collection Biblioteca Comunale dell'Archiginnasio, Bologna, Italy.

the seahorse being among these. Such images, probably influenced by mythology, could have also contributed to Arantius' attempts to describe the structure of the hippocampus. 3,23

In 1579, from Arantius' experience and data in observational and experimental science in human anatomy, Observationes Anatomicae was first published. The first 8 chapters included descriptions about the brain and ventricles. In the first edition of Observationes Anatomicae (1579) and a later version (Observationes Anatomicae: De Humano Foetu) in 1587, Arantius used the term seahorse, or hippocampus, to describe this small organ as the ridge or structure in the temporal horn of the lateral ventricle. It is now generally accepted that Arantius is the pioneer of the hippocampal discovery and terminology. However, although Arantius was recognized for the discovery of the hippocampus, his use of the term only referred to one part rather than the entire segment, the way it is used today. Thus, the term hippocampus emerged more or less as a puzzle to later scholars, who proposed various other terms for it including Ammon's horn. ${ }^{23}$

\section{Hippocampus; Historical Evolution}

Although the discovery and importance of the hippocampus has been an attractive subject of repeated reviews, the actual origin of the name and the meaning of the term 
hippocampus itself has been noted by just a few. Initially Arantius assigned the name white silkworm (Bombycinus vermis candidus) to it, and thereafter seahorse (hippocampus). Arantius decribed the hippocampus in his own words in the first chapter of his book De Humano Foetu Liber in 1587, which is reproduced here. ${ }^{9}$

\begin{abstract}
Horum ventriculorum basi, quae intro ad medium respicit, candida insurgens supereminet,\& quasi adnascitur substantia, quae $\mathrm{ab}$ inferiori superficie, velut additamentum extollitur, psalloidique corpori, seu testudini est continua, ac per longitudinem, in anteriora, versus frontem protenditur inequalique, ac flexuosa figura predita est, quae Hippocampi, hoc est marini equuli effigié refert, vel potius, bóbycini vernis cádidi spinalis medullae initium hinc inde amplexantis, formá indicant, de cuius usu alibi dicemus: huius particula caput referens tertio vocato ventriculo proxima est, reflexum vero corpus in caudam abiens, ad anterior protéditur; quocirca ad superiorum differentiam, Hippocampi, vel Bombycini vermis ventriculos appellare libuit. Illud praeterea observatione dignum relinquitur, quod plexu e sinuum basi sublato, elegans quedam, atque admirabilis, exiguorum quamvis vasorum, propagation cóspicitur, quae in superioribus non est adeo artificiosa. Quod ad cavitates, \& reliqua, sic habet.
\end{abstract}

Therefore, it is obvious that Arantius was not completely biased in comparing the hippocampus with a seahorse.

As detailed in Lewis, ${ }^{10}$ when De Humano Foetu Liber was published, Pierre Belon, Guillaume Rondelet, and Albertus Magnus had already criticized the description of the hippocampus proposed by Arantius. They thought the word hippocampus was literally "horse-caterpillar" (combining horse and larva of moth together). Therefore, they instead compared the hippocampus with the steed (an imaginary creature originated from the head of a horse and the fin of a dolphin) of the Roman god of water, Neptune, or a dolphin itself instead of a seahorse. ${ }^{10}$ Like Arantius, German anatomist Duvernoy hesitated between the terms seahorse and silkworm while he was illustrating the structure of the hippocampus for the first time in 1729. ${ }^{3}$ Thereafter, Danish anatomist Jacob Winslow proposed the name "ram's horn" (1732) for the hippocampus, and his fellow, de Garengeot, suggested another term, "cornu ammonis," or the horn of Amun (an ancient Egyptian god). ${ }^{13,16}$ Dutch biologist van Diemerbroeck in 1672 named it "pes hippocampi." Importantly, French anatomist Pierre Tarin (1750) distinguished the dentate gyrus from the other parts of the hippocampus and named it "dentate fascia." Subsequently, in the 18th century, Félix Vicq d'Azyr identified the hippocampus major and minor, which sparked a debate about Darwin's theory of evolution in respect to anatomical findings between Thomas $\mathrm{H}$. Huxley and Richard Owen in 19th century Victorian England. Finally, the debate was concluded in favor of Huxley and Darwin's theory. ${ }^{14}$

Golgi (1873) introduced the silver impregnation method (black reaction) to better understand the microscopic structure of the nervous system, and that method was modified by Ramon y Cajal. ${ }^{18}$ This was a great advancement in studying the cellular architecture of the hippocampus. Subsequently, the Papez circuit was reported as a center of emotion by James Papez in 1937, and the hippocampus was articulated in the circuit. ${ }^{15}$ However, later on (in 1952) MacLean introduced the Papez circuit as part of the limbic system. ${ }^{11}$ Thus, from the above discussion it is obvious that a certain vagueness remains regarding the terminology and anatomical description of the hippocampus. ${ }^{23}$ Frederic T. Lewis expressed his dismay about the discovery of the hippocampus by saying that Arantius made a great mistake by giving two names for a single newly discovered brain structure and not describing it properly. He criticized by saying that it was the worst anatomical description so far. Moreover, he told that the way Arantius pictured the seahorse may remain unknown forever, but that comparing the hippocampus with dolphins was more or less appropriate..$^{10,20}$ However, in the literature the term hippocampus has become the most widely used, and has been used until now. The Latin word hippocampus was coined from the Greek word hippokampos (hippos meaning "horse" and kampos meaning "sea monster"). Therefore, Arantius is credited and recognized today for the term hippocampus. ${ }^{16,23}$ Last, in 1998, the Federative Committee on Anatomical Terminology decided to refer to the term hippocampus as "Hippocampus proper" and/ or "Ammon's horn" (Fig. 2).

\section{Other Anatomical Discoveries of Arantius}

Besides the hippocampus, Arantius demonstrated the fourth ventricle of the human brain. He identified the superior levator palpebrae muscle and acknowledged that the extraocular muscles originate from the orbit, not from the dura mater. He described how the optic nerve enters into the lateral side of the orbit. He identified that the coracobrachialis is a separate muscle in the upper extremity. Arantius demonstrated the different cardiac structures, including cartilaginous nodules in the semilunar valve (nodules of Aranzio), foramen ovale, ductus arteriosus, and ductus venosus, and acknowledged the postnatal closure of the foramen ovale and ductus arteriosus. He described the characteristics of the gravid uterus and presented the finest details about the fetus. Moreover, he was the first anatomist to describe the deformed pelvis and acknowledged the indication of cesarean section for the deformed or narrow pelvis. Last, he also characterized the fetal circulatory system. ${ }^{6,7,23}$

\section{Publications}

As a famous anatomist, Arantius had numerous publications. He published his book De Humano Foetu Liber in Rome (1564), in Venice (first edition in 1571, second edition in 1587, and third edition in 1595) and in Basil (1579). His publication Observationes Anatomicae was published in Venice (1587 and 1595 [Fig. 3]) and in Basil (1579). He wrote the book De Tumoribus Secundum Locos Affectos, which was published in Banon (1571) and Venice (1587). The combined publication of these books was reported in Venice (1587) and is currently available as a microfilm at Louise M. Darling Biomedical library, University of California Los Angeles. In addition, Arantius wrote a commentary called "Hippocratis Librum de Vulneribus Capitis Commentarius brevis" in $1580 .^{6}$ As a surgeon he also contributed to the study of various surgical techniques, including nasal reconstruction surgery, and he published different books on surgery. 

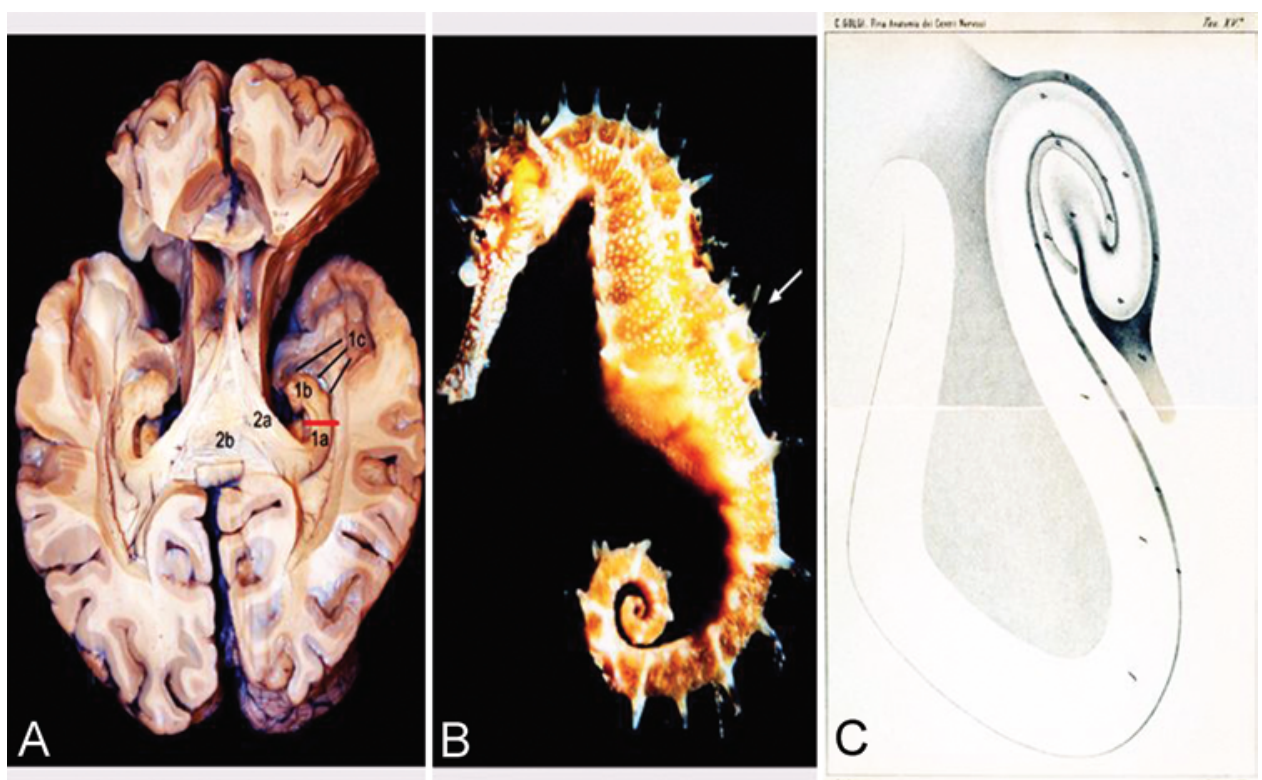

FIG. 2. Comparison of the hippocampus with a seahorse. A: Photograph of the cerebrum seen from above and revealing the hippocampus. Copyright Tamàs Sebesteny. Published with permission. B: Photograph of a seahorse from the Gulf of Aqaba, Red Sea. National Oceanic and Atmospheric Administration (NOAA) Photo Library, Photographer: Mohammed Al Momany, (http:// www.photolib.noaa.gov/htmls/reef2027.htm). C: Drawing of the hippocampus from Golgi C: Sulla fina anatomia degli organi centrali di sistema nervoso. V. Sulla fina anatomia di grande piede d'Hippocampo. Milan: Ulrico Hoepli, 1886. Figure is available in color online only.

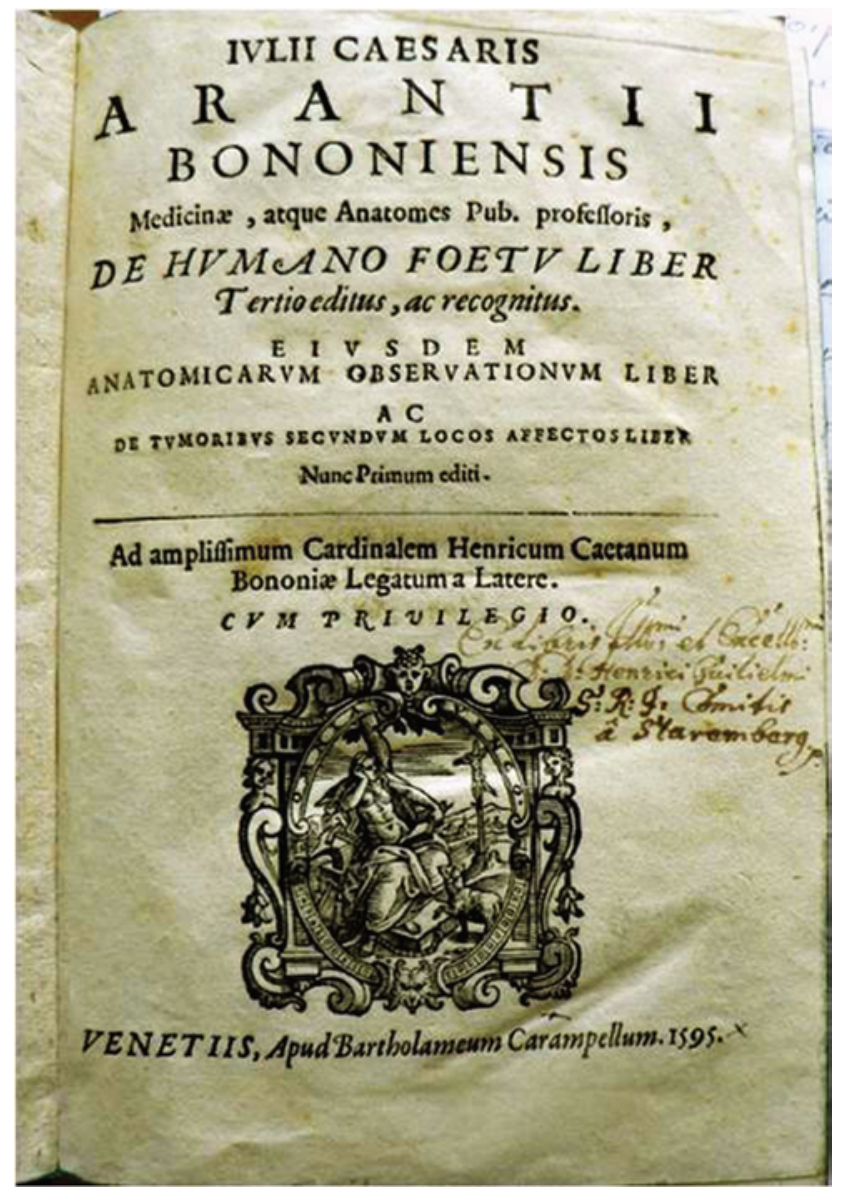

FIG. 3. Cover page of De Humano Foetu Liber, published in Venice in 1595. Figure is available in color online only.

\section{The Hippocampus in the Modern Age and Its Functional Aspect}

The understanding or description of the hippocampus' function was somewhat restricted to the regulation of olfaction until the beginning of the 20th century. Once Paul Broca identified the hippocampal formation as a part of the limbic lobe (hippocampus with surrounding structure, 1878) and James Papez depicted the Papez circuit (1937), ${ }^{15}$ the function of the hippocampus was widely explored as a regulator of emotional behavior. However, later on MacLean further articulated the Papez circuit as part of the limbic system (limbic lobe with hypothalamus and amygdala) in 1952, and further supported the behavioral function of the hippocampus. ${ }^{11}$ In 1953, from an experimental operation (removal of both hippocampi), it was found that the hippocampus was involved in both memory and learning processes. ${ }^{1,2}$ Current theories suggest that the hippocampus proper plays a major role in long-term memory and spatial learning, whereas parahippocampal and entorhinal cortices are involved in semantic memory. ${ }^{8,17,19}$ Last, animal studies have revealed that the hippocampus also plays a role in eating behavior. ${ }^{21}$

\section{Conclusions}

The discovery of the hippocampus by Arantius is an immense contribution in the field of neuroanatomy. In addition, Arantius had vast knowledge not only in neuroanatomy but also in other anatomical fields, predominantly from his observational and experimental studies. He should be highly honored in the field of neuroanatomy for his contribution to the anatomical discovery of the hippocampus and other structures of the human brain. 


\section{References}

1. Barr WB, Goldberg E: Pitfalls in the method of double dissociation: delineating the cognitive functions of the hippocampus. Cortex 39:153-157, 2003

2. DeJong RN: The hippocampus and its role in memory. Clinical manifestations and theoretical considerations. J Neurol Sci 19:73-83, 1973

3. El-Falougy H, Benuska J: History, anatomical nomenclature, comparative anatomy and functions of the hippocampal formation. Bratisl Lek Listy (Tlacene Vyd) 107:103-106, 2006

4. Gaspare Tagliacozzi, (1545-1599) plastic surgeon. JAMA 207:1343-1344, 1969

5. Golgi C, Bentivoglio M, Swanson L: On the fine structure of the pes Hippocampi major (with plates XIII-XXIII). 1886. Brain Res Bull 54:461-483, 2001

6. Gurunluoglu R, Gurunluoglu A: Giulio Cesare Arantius (1530-1589): a surgeon and anatomist: his role in nasal reconstruction and influence on Gaspare Tagliacozzi. Ann Plast Surg 60:717-722, 2008

7. Gurunluoglu R, Shafighi M, Gurunluoglu A, Cavdar S: Giulio Cesare Aranzio (Arantius) (1530-89) in the pageant of anatomy and surgery. J Med Biogr 19:63-69, 2011

8. Jarrard LE: What does the hippocampus really do? Behav Brain Res 71:1-10, 1995

9. Judaš M, Pletikos M: A note on the sea-horse in the human brain. Transl Neurosci 1:335-337, 2010

10. Lewis FT: The significance of the term hippocampus. J Comp Neurol 35:213-230, 1923

11. MacLean PD: Some psychiatric implications of physiological studies on frontotemporal portion of limbic system (visceral brain). Electroencephalogr Clin Neurophysiol 4:407-418, 1952

12. Moser MB, Moser EI: Functional differentiation in the hippocampus. Hippocampus 8:608-619, 1998

13. Olry R, Haines DE: Cerebral mythology: a skull stuffed with gods. (Neurowords 3). Hist Neurosci 7:82-83, 1998

14. Owen CM, Howard A, Binder DK: Hippocampus minor, calcar avis, and the Huxley-Owen debate. Neurosurgery 65:1098-1105, 2009

15. Papez JW: A proposed mechanism of emotion. 1937. J Neuropsychiatry Clin Neurosci 7:103-112, 1995

16. Pearce JM: Ammon's horn and the hippocampus. J Neurol Neurosurg Psychiatry 71:351, 2001

17. Suzuki WA, Clayton NS: The hippocampus and memory: a comparative and ethological perspective. Curr Opin Neurobiol 10:768-773, 2000

18. Swanson LW: Camillo Golgi on the structure of the hippocampus. J Hist Neurosci 8:164-169, 1999

19. Teyler TJ, DiScenna P: The role of hippocampus in memory: a hypothesis. Neurosci Biobehav Rev 9:377-389, 1985

20. Tilney F: The hippocampus and its relations to the corpus callosum. J Nerv Ment Dis 89:433-513, 1939

21. Tracy AL, Jarrard LE, Davidson TL: The hippocampus and motivation revisited: appetite and activity. Behav Brain Res 127:13-23, 2001

22. van de Graaf RC: When and how did Giulio Cesare Arantius (1530-1589) learn to perform nasal reconstructions? Ann Plast Surg 63:116-117, 2009 (Letter)

23. Walther C: Hippocampal terminology: concepts, misconceptions, origins. Endeavour 26:41-44, 2002

\section{Author Contributions}

Drafting the article: Bir. Critically revising the article: all authors. Reviewed submitted version of manuscript: all authors. Approved the final version of the manuscript on behalf of all authors: Nanda.

\section{Correspondence}

Anil Nanda, Department of Neurosurgery, LSU HealthShreveport, 1501 Kings Hwy., Shreveport, LA 71130-3932. email: ananda@1suhsc.edu. 